\title{
Price regulation and generic competition in the pharmaceutical market
}

\section{Dag Morten Dalen}

Norwegian School of

Management and the Frisch

Centre

\section{Steinar Strøm}

University of Oslo, University of Turin and the Frisch Centre

\section{Tonje Haabeth}

University of Oslo and the Frisch Centre

\section{UNIVERSITY}

\section{OF OSLO}

HEALTH ECONOMICS RESEARCH PROGRAMME

Working paper 2006: 1

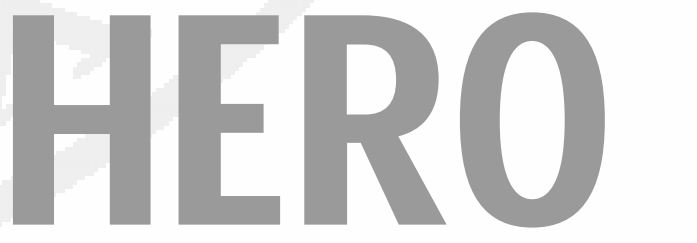




\title{
Price regulation and generic competition in the pharmaceutical market
}

\author{
Dag Morten Dalen, Steinar Strøm \\ Tonje Haabeth
}

\begin{abstract}
Health Economics Research Programme at the University of Oslo HERO 2006
\end{abstract}

Keywords: $\quad$ Discrete choice, demand for pharmaceuticals, monopolistic competition, evaluation of yardstick based price regulation

JEL classification: C35, D43, I18, L11

Correspondence to: Steinar Strøm, Department of Economics, Postboks 1095 Blindern NO-0317 Oslo, Norway. E-mail: steinar.strom@econ.uio.no 



\begin{abstract}
In March 2003 the Norwegian government implemented yardstick based price regulation schemes on a selection of drugs experiencing generic competition. The retail price cap, termed "index price”, on a drug (chemical substance) was set equal to the average of the three lowest producer prices on that drug, plus a fixed wholesale and retail margin. This is supposed to lower barriers of entry for generic drugs and to trigger price competition. Using monthly data over the period 1998-2004 for the 6 drugs (chemical entities) included in the index price system, we estimate a structural model enabling us to examine the impact of the reform on both demand and market power. Our results suggest that the index price helped to increase the market shares of generic drugs and succeeded in triggering price competition.
\end{abstract}





\section{Introduction}

When a pharmaceutical patent expires, generic firms may enter the market and start selling copies of the original drug. As generic drugs contain exactly the same active chemical substances, these are certified to be perfect substitutes to the original branded drugs. In competitive markets entry of firms producing perfect substitutes would trigger fierce price competition, bringing monopoly rents enjoyed by the original patent holder to an end. Scale economies are not considered to be important in production of already innovated drugs. As reported by Caves et al. (1991), the fermentation technologies extensively used to produce the active chemical entities are batch processes carried out on small scale, and the production capacity for assembling active and inert ingredients into pills or capsules is largely flexible. Thus, looking at the supply side only, drug prices above marginal costs after patent expiration are expected to induce entry by generic producers.

Although generic entry has become more extensive both in Europe and the US, it is well known that entry of generic drugs appears to be gradual in many countries (Berndt et al. 2002). Brand name producers are often able to maintain a high-price strategy instead of engaging in fierce price competition with generics. Both theoretical and empirical research have shown that the brand name producer may choose to meet generic competition by raising prices, targeting the market segment that remains loyal to the branded drug.

The persistence of demand for branded drugs when cheaper perfect substitutes become available means that physicians and patients develop choice habits that are not easily changed (see Hellerstein (1998) and Stern and Trajtenberg (1998)). Doctors may become loyal to some drug companies, which may steer their choice of drugs irrespective of the price. Habit formation is of particular importance in this market since physicians do not have economic incentives to let drug prices affect their choices, or to keep themselves informed about new generics entering the market. Physicians have incentives to serve the 
interests of their patients, but the insurance schemes in many countries make the patient ignorant about drug prices. In most countries, therefore, drug prices are subject to regulation. Regulating prices, when the drug producer has a patent, and only imperfect substitutes are available, involves bilateral bargaining that leaves some market power to the producer. Once patent protection expires, and generic producers may enter, regulation can be substantially improved by introducing benchmarking schemes.

The aim of this paper is to study competition between generics and branded drugs in the Norwegian market, and in particular, how competition responded to a recent regulatory reform involving benchmarking. There is an extensive literature on the effect of generic entry on prices, but few examples of empirical studies of the performance of price regulation schemes as such. The reform in Norway represents a unique policy experiment allowing us to investigate the performance of yardstick based price regulation.

For this purpose we develop an empirical model with two components. First, we estimate a demand model in which doctor-patient's choices follows from a discrete choice structure with random utility function, which implies multinomial logit choice probabilities. Second, assuming that the drug producers set prices non-cooperatively to maximize profit and adhering to our estimated price elasticities, we derive a timeconditioned measure of market power - the Lerner index - for each product. Our model belongs to the class of models studied by Berry (1994) and Berry et al. (1995).

Our results suggest that the yardstick based price scheme had a significant impact on market power. Generic drugs experience a significant increase in demand after the reform, and the estimated first order regressive process of market power reveals that competition works. Furthermore, the estimated effect of yardstick-based regulation on demand indicates reduced market power.

Several studies provide insights on the nature of competition in the market for pharmaceuticals after patent expiration. Grabowski and Vernon (1992) examine the effect of generic entry in the US market on prices for 18 drugs that were first exposed to generic 
competition during the years 1983 through 1987. Their descriptive statistics reveal that the branded drug price increased by an average of 7 percent one year subsequent to generic entry and 11 percent two years after generic entry. At the same time generic prices continue to fall after first entry. The average generic price two years after entry was 35 percent lower than the first entry price.

Frank and Salkever (1997) arrived at similar results when they looked at a sample of 32 drugs that lost patent protection during early to mid-1980s. More competition among generic drug producers is found to cause price reductions for those drugs. Increased competition from generic drugs, however, is not accompanied by lower prices on branded drugs. Their results suggest instead a small price increase on branded drugs. Caves et al. (1991) investigate the experience of 30 drugs that lost patent protection between 1976 and 1987. Their result differs from that of Frank and Salkever (1997). The branded drug price declines with the number of generic entrants, but the rate of decline is small. For the mean number of generic drugs, the brand name price declines by 4.5 percent only. At the same time, generic prices are much lower than the brand name prices. Their results suggest that average generic price is about 50 percent of the branded drug price when 3 generic producers have entered the market.

Whereas these studies concern the effect of competition on prices, Hudson (2000) reports results on the determinants of generic entry itself. In his data 70 percent of the 50 chemical entities that went of off patent in the years 1985-1996 were taken up by generic firms in the US market. The extent of generic entry varies between countries. In the UK market, for example, only 37 percent of the drugs were taken up by generic producers. Market size in terms of sales value increases the likelihood of generic entry.

Our focus is on the effect of regulatory schemes, and not on the competition between branded and generic drugs. Pavcnik (2002) offers a recent study of regulatory schemes. With use of data from the German market, she investigates what effect the introduction of reference-pricing had on competition between branded and generic drugs. Drug prices are found to drop after the introduction, and generic competition is shown to play an 
important role in this process. The price on branded drugs fell on average by more than the price on generic drugs. The price drop on branded drugs increases with the number of generics in the market. Winkelmann (2004) studies another aspect of the statutory health insurance in Germany. The prescription fee paid by the patient increased substantially in 1997. This price increase on prescription drug is found to reduce the number of doctor visits on average by 10 percent.

The plan of the paper is at follows. Section 2 gives a brief overview of the Norwegian market for pharmaceuticals and its reforms. Section 3 presents the data used in the analysis. Our demand model is specified in Section 4, and the price setting part is presented in Section 5. Section 6 presents estimates and Section 7 concludes.

\section{The pharmaceutical market in Norway}

As in most other countries the pharmaceutical market in Norway is subject to regulation. Regulation of prescription drugs concerns both producers' entry and pricing decisions and the pharmacies' retail margins, whereas the regulation of OTC drugs concerns entry decisions only. The regulatory authority related to the pharmaceutical sector is the Norwegian Ministry of Health and Social Affairs. The Ministry, and its agency (Norwegian Medicines Control Authority) control the entry of new type of drugs, the wholesale prices, and the retail margins. The manufacturer price is not regulated.

The Norwegian Health System offers a statutory public health insurance, and close to 70 percent of total drug expenses are covered by this insurance scheme. These expenses have been increasing rather rapidly due to an ageing population and entry of new and more expensive drugs. Looking at drugs that are approved for reimbursement by the social insurance schemes, the share of total cost paid by the patient amounts to 11 percent in Norway. This is much lower than in other Nordic countries. In Denmark this share 
amounts to 42 percent, while in Sweden the patients cover 26 percent. In UK, Spain, and France the patients pay only 6-7 percent of total costs. ${ }^{2}$

During the last decade several reforms have been implemented to encourage switching to generic drugs. Parallel imports were introduced in 1998, and pharmacists were allowed to keep 50 percent of the savings if they were able to obtain lower prices on these drugs. In 1999 doctors were required to prescribe the generic with the lowest price. However, this recommendation and the reference price system used proved not sufficient to increase physicians' awareness on prices.

In Norway two recent reforms have been introduced to foster competition and to lower prices. Generic substitution was introduced in March 2001. Generic substitution ensures that the actual choice of drug producer is made less dependent on physicians' prescription policy. For a sample of about 100 drugs (chemical substances), pharmacies were permitted to substitute a generic for a branded drug, independent of which producer that was prescribed by the physician. Being permitted to intervene between the physician and the patient, the pharmacies now have an important influence on whether the branded drug or a generic drug is chosen. Generic substitution, therefore, is expected to lower barriers to entry for generic drugs by reducing the importance of prescription habits for actual drug choices in pharmacies. The problem with this scheme turned out to be that vertically integrated wholesalers ${ }^{3}$ and retailers could still sell these (cheaper drugs) at prices equal to the fixed price cap. No link was introduced between the wholesalers' input prices (producer prices) and the retailers' price caps (see Razzolini, 2004).

With the reform of March 2003 such a link was established. The retail price cap, termed "index price”, on a drug (chemical substance) was updated every third months and set equal to the average of the three lowest reported producer prices on that drug, plus a fixed

\footnotetext{
${ }^{2}$ LMI (2005). All figures are 2002-observations.

${ }^{3}$ Generic substitution was introduced together with a substantial liberalization of the pharmacy market. With the new pharmacy act of 2001 restrictions on ownership were abolished, and most of the pharmacies were sold to the three main wholesalers. The Norwegian market is now characterized by having three vertically integrated distribution companies, without legal regulation on entry of new companies or pharmacy outlets.
} 
distribution (wholesale and retail) margin. If a retailer selects a producer with a price exceeding the average of the three lowest prices, the net margin of the integrated retailerwholesale pharmacy firm drops, whereas a retailer selecting a producer with a lower producer price experiences an increase in his net margin. The reform is both expected to trigger price competition between producers and to reduce the retail prices.

\section{Data}

The dataset is provided by the Norwegian Social Insurance Agency, and covers monthly observation of the six chemical substances included in the index price system. The data are collected at 22 pharmacies in Norway in the period 1998-2004. The sample of pharmacies is considered to be representative for the sale of drugs in Norway. The main variables reported by the pharmacies are volume of sale, both in retail value (NOK) ${ }^{4}$ and number of defined daily doses (DDD) for each product. These are used to calculate the prices per DDD and market shares of each product within the submarket (chemical substance).

Note that the number of products exceed the number of producers of a chemical substance because a drug is sold in different versions according to strength, representation form (pills or fluid) and package size. For each of the six chemical substances, we have selected the version with the highest sales value. The chemical substances subjected to index price regulation, and covered by our data, are given in Table 1.

\footnotetext{
${ }^{4}$ As of Nov 2005 1USD is around NOK 6.80
} 
Table 1: Sample of drugs

\begin{tabular}{|c|c|c|c|c|}
\hline ATC-code & Generic name & Indication & $\begin{array}{l}\text { Brand name } \\
\text { producer }\end{array}$ & $\begin{array}{l}\text { First entry of } \\
\text { generica }\end{array}$ \\
\hline A02BC01 & Omeprazol & Ulcer & AstraZeneca & November 2001 \\
\hline C09AA02 & Enalapril & $\begin{array}{l}\text { High blood } \\
\text { pressure }\end{array}$ & MSD Norge & $\begin{array}{l}\text { October } \\
2000\end{array}$ \\
\hline C09AA03 & Lisinopril & $\begin{array}{l}\text { High blood } \\
\text { pressure }\end{array}$ & $\begin{array}{l}\text { AstraZeneca, } \\
\text { MSD Norge }\end{array}$ & November 2000 \\
\hline N06AB04 & Citalopram & Depression & H.Lundbeck & $\begin{array}{l}\text { May } \\
2002\end{array}$ \\
\hline R06AE07 & Cetirizin & Allergy & UCB Pharma & $\begin{array}{l}\text { February } \\
2002\end{array}$ \\
\hline R06AX13 & Loratadin & Allergy & ScheringPlough & $\begin{array}{l}\text { April } \\
2002\end{array}$ \\
\hline
\end{tabular}

The products are classified as the branded drug (original patented product), parallel imported branded drug, or generic drug.

In Appendix A we report the development of prices and market shares for the products in these six markets. The time period is 1998-2004. We observe that prices and market shares of the branded drugs started to decline a little before the generics entered the market. The decline in the market shares of the branded drugs prior to entry of generics is due an increase in the market share of the parallel imports, from lower price countries such as Spain and Greece. When generics enters the market there are a further decline in the market share of the branded drugs and a further drop in the prices of branded drugs.

\section{A demand model}

The institutional settings in the pharmaceutical market define a complex mechanism for drug choices. Demand for drugs is often assumed to follow from the doctor's choices as the patient's agent. Looking at submarkets with generic substitution, pharmacies may intervene in the actual choice of drug. Total demand for a drug, with a given chemical substance, is still determined by the doctors, but pharmacies become important for the 
actual choice of producer within the market defined by the chemical substance. As explained above, pharmacies are required by law to substitute the prescribed product with a cheaper product/producer (if available). Importantly, both the patient and the doctor are allowed to prevent substitution. The doctor can add a reservation to the prescription, which prohibits pharmacies to substitute. Even without such a reservation, the patient may insist on the prescribed product. In that case, the insurance scheme does not cover the price difference between the prescribed product and the cheapest available. The difference has to be paid by the patient himself.

We assume that the doctor/patient-alliance's choice maximizes the utility of the patient. All patients are assumed to have the same deterministic part of the indirect utility. Let $I_{m}$ be the number of drugs (producers) available in market $m$. A market is defined by the chemical substance (lowest level of the ATC-code). The indirect utility from drug $i=1,2,, \mathrm{I}_{\mathrm{m}}$ in market $m, m=1,2, . .6$ in month $t$, by patient/doctor $n$ is random, and given by

$$
U_{i m n t}=g_{i m t}+a_{i m t} P_{i m t}+e_{i m n t},
$$

where $P_{i m t}$ is the price of drug $i$ in market $m$ at time $t . g_{i m t}$ is a drug specific effect, and $e_{i m n t}$ is a random variable iid extreme value distributed across drugs, markets, patients/doctors and time. Heterogeneity in patient/doctor preferences is represented by the iid error term. $a_{i m t}$ is a coefficient related to price.

The probability that patient/doctor $n$ will choose drug $i$ in market $m$ at time $t$ is given by

$$
\begin{aligned}
& \operatorname{Pr}\left(U_{i m n t}=\max _{j} U_{j m n t} \mid \mathrm{i}, j=1,2,,, I_{m t}, m=1,2,,, 6\right)= \\
& \varphi_{\text {imt }}=\frac{\exp \left(g_{i m t}+a_{i m t} P_{i m t}\right)}{\sum_{j=1}^{I_{m t}} \exp \left(g_{j m t}+a_{j m t} P_{j m t}\right)} ; i=1,2, I_{m t}, m=1,2,,, 6
\end{aligned}
$$


Let drug number 1 in all markets be the branded drug. We then observe that

$$
\begin{aligned}
& \frac{\varphi_{\text {imt }}}{\varphi_{1 \mathrm{mt}}}=\exp \left(\left(\mathrm{g}_{\mathrm{imt}}-\mathrm{g}_{1 \mathrm{mt}}\right)+\left(\mathrm{a}_{\mathrm{imt}} \mathrm{P}_{\mathrm{imt}}-\mathrm{a}_{1 \mathrm{mt}} \mathrm{P}_{1 \mathrm{mt}}\right)\right) \\
& \text { and } \\
& \ln \frac{\varphi_{\text {imt }}}{\varphi_{1 \mathrm{mt}}}=\mathrm{g}_{\mathrm{imt}}-\mathrm{g}_{1 \mathrm{mt}}+\mathrm{a}_{\mathrm{imt}} \mathrm{P}_{\mathrm{imt}}-\mathrm{a}_{1 \mathrm{mt}} \mathrm{P}_{1 \mathrm{mt}} ; \mathrm{i}=2,,, \mathrm{I}_{\mathrm{mt}}
\end{aligned}
$$

Because all individuals have the same deterministic part of the utility function, the observed parallel to the log of the relative probabilities equals the log of the market share of drug $i$ relative to the market share of drug 1 .

We assume that

$$
\mathrm{g}_{\mathrm{mit}}=\mathrm{g}_{\mathrm{im}}+\mathrm{v}_{\mathrm{imt}} ; \mathrm{i}=1,2,,, \mathrm{I}_{\mathrm{mt}}
$$

$\mathrm{g}_{\text {im }}$ is a constant that varies across drug types and reflects some attributes of the drugs beyond price. Although these drugs are very close substitutes, since they all contain the same active ingredients, there are still reasons to believe that drug specific effects are present. One reason is that the drugs differ with respect to inert ingredients, shape, packaging and labeling. In addition, the producers run advertising campaigns that might affect the doctors' choice of a certain drug (see Scott Morton, 2000, and Coscelli, 2000).

The parameter $v_{i m t}$ is a random variable assumed to have zero expectation, with constant and equal variance across drugs, markets and time, assumed uncorrelated across drugs, markets and time.

A general characteristic of the drug market is that branded drugs are able to maintain large market shares and high prices after the entry of cheaper generic drugs. Although generic drugs enter with substantial lower prices, demand responds are often weak. To 
capture this, we allow branded and generic drugs to have different price responses. Moreover, the price response on demand for generic drugs are allowed to depend on the market age of the specific drug:

$$
a_{i m t}=a_{0}+a_{1} G D_{i m t} \frac{A_{i m t}}{A_{1 m t}}
$$

Here $a_{0}$ is a constant that we expect to be negative since it captures the direct effect of price on demand. This direct price response is assumed the same across drugs and markets.

$G D_{i m t}$ is a dummy variable. $G D_{i m t}=1$ if drug $i$ in market $m$ is a generic drug. Since parallel imported branded drugs are not treated as generic drugs, not all drugs $i \neq 1$ are generic drugs. $A_{i m t}$ equals the number of months drug $i \neq 1$ has been on the market. Thus the ratio of $A_{\text {imt }}$ to $\mathrm{A}_{1 \mathrm{mt}}$ measures the "market age" of drug $i$ relative to the "market age" of the branded product. If the drug has been in the market since 1998, the ratio is equal to one. For younger drugs, the ratio takes values less than one. Total price response for the branded drug is captured by the direct effect $a_{0}$, whereas for the generic drugs "the market age" of the drug is allowed to matter. If, for given prices, generic drugs experience increased demand as market age increases, $a_{1}$ will be positive.

The new regulation scheme, the index price system, was introduced March 2003. In order to identify the effect on demand for generic drugs, we represent this new policy in our log odds ratio equation above by the variable $\tau_{\mathrm{t}}$, which takes the value 1 for $\mathrm{t}=$ March 2003 and the following months, and 0 otherwise.

Thus the log odds ratio that we estimate is the following 


$$
\ln \frac{\varphi_{i m t}}{\varphi_{1 m t}}=g_{m i}+a_{0}\left(P_{i m t}-P_{1 m t}\right)+a_{1} G D_{i m t}\left[\frac{A_{i m t}}{A_{1 m t}} P_{i m t}-P_{1 m t}\right]+a_{2} G D_{i m t} \tau_{t}+v_{i m t}
$$

for $\mathrm{i}=1,2,, \mathrm{I}_{\mathrm{m}}, \mathrm{m}=1,2,, 6$ and $\mathrm{t}=\mathrm{Jan} 1998,$, Dec2004.

If the policy intervention succeeded, $a_{2}$ will be positive. For given prices, generic drugs will experience a positive shift in demand.

From (5) we can derive demand elasticities. Let $E_{i j m t}$ denote these elasticities and they are defined as the elasticity of demand of drug $i$ with respect to price of drug $j$. If $i=j$, we have the direct elasticities, otherwise we have the cross-price elasticities. Formally the elasticities are given by

$$
\begin{aligned}
& \mathrm{E}_{\mathrm{iimt}}=\frac{\partial \varphi_{\mathrm{imt}}}{\partial \mathrm{P}_{\mathrm{imt}}} \frac{\mathrm{P}_{\mathrm{imt}}}{\varphi_{\mathrm{imt}}}=\mathrm{a}_{\mathrm{imt}} \mathrm{P}_{\mathrm{imt}}\left(1-\varphi_{\mathrm{imt}}\right) \\
& \text { and } \\
& \mathrm{E}_{\mathrm{ijmt}}=\frac{\partial \varphi_{\mathrm{imt}}}{\partial \mathrm{P}_{\mathrm{jmt}}} \frac{\mathrm{P}_{\mathrm{jmt}}}{\varphi_{\mathrm{imt}}}=-\mathrm{a}_{\mathrm{jmt}} \mathrm{P}_{\mathrm{jmt}} \varphi_{\mathrm{jmt}} ; \text { for } \mathrm{i} \neq \mathrm{j}
\end{aligned}
$$

where $a_{i m t}$ is given in (4).

There are two important time effects on the direct price elasticity of generic drugs. Note that $a_{i m t}=a_{0}+a_{1} \frac{A_{i m t}}{A_{1 m t}}$ for a generic drug. If $a_{1} \geq 0$, the numerical value of the price coefficient $a_{i m t}$ decreases over time, and consequently the price elasticity of generic drugs decreases over time. This time effect is reinforced by the expected increase in market shares following the introduction of the index price reform. Increased market shares will, for given prices, reduce the price elasticity. Note that for the branded drugs $a_{i m t}=a_{0}$. If the reform works to increase market shares of generic drugs, there will be a corresponding increase in the own-price elasticity of branded drugs. 


\section{Market power}

We assume that the producers set prices in order to maximize expected profit, given the prices set by the other producers. Thus, the prices are set in a non-cooperative game of the Bertrand-Nash type.

Expected profit, denoted $\pi_{\mathrm{imt}}$ is given by

$$
\pi_{\mathrm{imt}}=\left(\mathrm{P}_{\mathrm{imt}}-\mathrm{c}_{\mathrm{imt}}\right) \mathrm{N}_{\mathrm{mt}} \varphi_{\mathrm{imt}}-\mathrm{K}_{\mathrm{imt}},
$$

where $\mathrm{c}_{\mathrm{imt}}$ is a constant unit cost of producing and distributing drug $i$ in market $m$ at time $t, \mathrm{~N}_{\mathrm{mt}}$ are the number of patients in market $m$ at time $t$, and $\mathrm{K}_{\mathrm{imt}}$ is fixed costs.

Maximizing $\pi_{\mathrm{imt}}$ with respect to price $\mathrm{P}_{\mathrm{imt}}$ gives the following price equation

$$
\mathrm{P}_{\mathrm{imt}}=\mathrm{c}_{\mathrm{imt}}+\frac{1}{-\mathrm{E}_{\mathrm{iimt}}}
$$

An indicator of market power is the so-called Lerner index, defined as

$$
\mathrm{L}_{\mathrm{imt}}=\frac{\mathrm{P}_{\mathrm{imt}}-\mathrm{c}_{\mathrm{imt}}}{\mathrm{P}_{\mathrm{imt}}}
$$

Inserting the price equation (8), we get

(10) $L_{\text {imt }}=\frac{1}{-E_{\text {iimt }} P_{\text {imt }}}=\frac{1}{a_{\text {imt }} P_{\text {imt }}^{2}\left(1-\varphi_{\text {imt }}\right)}$

By convention we set $\mathrm{L}_{\mathrm{imt}}=1$ when there is a monopoly. We note that under perfect competition $\mathrm{L}_{\mathrm{imt}}=0$. 
If competition works, high price-cost margins in the market would attract entry of generics. When the maximal market power is high, as measured by the Lerner index, more firms will enter and profit margins will gradually be reduced. If this is the case, the market power that firm $i$ in market $m$ can obtain at time $t$ follows a first order regressive process. To investigate whether this mechanism is at work in the Norwegian pharmaceutical market, we estimate the following market power equation:

$$
\mathrm{L}_{\mathrm{imt}}=\mathrm{b}_{\mathrm{im}}+\mathrm{b}_{\max } \mathrm{L}_{\mathrm{mi}(\mathrm{t}-1)}+\mathrm{u}_{\mathrm{imt}}
$$

Competition works if $\mathrm{b}<1$, and the expected long run maximal market power, denoted $L_{m}^{*}$ will be given by

$$
\mathrm{L}_{\mathrm{m}}^{*}=\frac{\mathrm{b}_{\mathrm{m}}}{(1-\mathrm{b})}
$$

where $b_{m}$ is the average of the fixed effects, $b_{i m}$.

\section{Results}

Estimation is performed in two steps. First, we estimate the demand model in order to identify the price effects on the demand - both branded and generics - and the effect of the index price model. Second, using information on price elasticities acquired from step one, we calculate the producer specific Lerner index and estimate the Lerner index process equation.

Endogeneity bias problems may arise when the unknown coefficients in the demand equations (5) are estimated by OLS. The reason is that the prices occurring on the right hand side in (4) depends on the market share through the price setting equations (8). There are thus good reasons to believe that unobserved elements in price setting are correlated with the error terms in the market share equations. 
To obtain unbiased estimates we can either try to specify the joint probability for random market shares and random prices (and estimate the unknown coefficients in a full information maximum likelihood procedure) or to use instrument variables. We will apply the latter procedure and instrument prices.

We have instrumented the prices in a two stage least square procedure. First, prices are estimated on instruments, and then the predicted values of prices are used in the demand equations. The instrument variables used in the first stage price regression should be variables that affect the supply side and are uncorrelated with the error terms in the demand equations. Good instruments are thus correlated with costs (cost-shifters), but not with unobserved quality of the drugs we are considering.

We have used two instruments. The first instrument is the price of similar drugs, with the same chemical substance, but with much higher strength. Drugs of different strengths are used against different illnesses or different degrees of illnesses. This instrument is correlated with costs because the molecules and the other inactive substances in the drugs are the same. This is a strong instrument, but the markets of drugs with different strength differ with respect to number of drugs on the market, and moreover the entry of generics occurs at different dates. The level of competition is thus different in the different markets. See Hausman et al (1994) and Nevo (2000) for studies that have used prices on similar goods as instruments.

Following Brenkers and Verboven (2002) the quantity sold by the same producers in the Norwegian market, but with different atc codes, is used as the second instrument. We will argue that this variable contains useful information in a regulated and monopolistic market such as the pharmaceutical market. Sales of other drugs in the same markets signal that the producer has passed bureaucratic barriers related to regulations in the Norwegian market (familiarity) and also that the firm find it worth competing in this market (profitability). 


\section{Demand}

Estimation results are set out in the table below.

Table 2: Estimates of the demand equation

\begin{tabular}{lcccc}
\hline Coefficients & $\begin{array}{c}\text { Estimates without } \\
\text { instrument variables }\end{array}$ & t-values & $\begin{array}{c}\text { Estimates with } \\
\text { instrument variables }\end{array}$ & t-values \\
\hline $\mathrm{a}_{0}$ & -0.8324 & -6.34 & -2.1125 & -6.03 \\
$\mathrm{a}_{1}$ & 0.2607 & 3.52 & -0.1378 & -1.47 \\
$\mathrm{a}_{2}$ & 1.1594 & 8.12 & 2.3964 & 10.63 \\
$\overline{\mathrm{a}}_{\mathrm{m}}$ & & & & \\
$($ fixed effect & -0.1113 & -1.18 & -0.7697 & -5.52 \\
estimation) & & & & \\
\hline & 0.2034 & & & \\
$R^{2}$ & 1159 & & & \\
$\begin{array}{l}\text { Number of } \\
\text { observations }\end{array}$ & & & & \\
\hline
\end{tabular}

The direct effect of prices on demand is negative and significant. When the prices are instrumented, the direct price responses become numerical much higher. The impact of "market age" on demand is significantly positive when no instruments are used, but disappears when instruments are used. This implies that the marginal price response on markets shares are the same for branded and generic drugs, and represented by $a_{0}$. The development of price elasticities over time, therefore, will be driven by changes in markets shares due to the index price and entry of producers. The impact of the yardstick based price regulation on demand for generic drugs is significant and positive in both models. Using instruments, the effect becomes stronger.

In the next table we show the direct price elasticities, derived from the above estimates and evaluated at sample average values, for the six different markets and hence six different chemical substances. 
Table 3: Estimated price elasticity

\begin{tabular}{lc}
\hline Chemical substance $(\mathrm{m})$ & Estimated elasticity, sample averages of $\mathrm{E}_{\mathrm{iimt}}$ \\
\hline A02BC01 : Omeprazol & -7.8 \\
C09AA02 : Enalapril & -1.6 \\
C09AA03 : Lisinopril & -2.4 \\
N06AB04 : Citalopram & -3.4 \\
R06AE07 : Cetirizin & -1.3 \\
R06AX13 : Loratadin & -1.6 \\
\hline
\end{tabular}

\section{Market power}

Using the estimated demand functions, we calculate the value of the Lerner index for each producer. In the next table we give the results from the estimation of the Lerner index AR(1) model

Table 4: Estimates of the market power equation.

\begin{tabular}{|c|c|c|}
\hline Coefficients & Estimate & t-value \\
\hline$\frac{\mathrm{B}}{\overline{\mathrm{b}}_{\mathrm{m}} \text { (fixed effects) }}$ & $\begin{array}{l}0.3720 \\
0.1812\end{array}$ & $\begin{array}{c}8.42 \\
10.81\end{array}$ \\
\hline $\begin{array}{l}R^{2} \\
\text { Number of } \\
\text { Observations }\end{array}$ & \multicolumn{2}{|c|}{344} \\
\hline
\end{tabular}

These estimates imply that in the long run the Lerner index approaches

$$
\frac{0.1812}{1-0.3720}=0.2866
$$


which means that average market power approaches a level around 28 percent above the perfect competitive case. This log run outcome is far below, around 72 percent, the initial monopoly case.

To illustrate the effect of the policy intervention on market power, we have calculated the average Lerner index with (Lerner 1) and without the policy intervention effect (Lerner 2). ${ }^{5}$ Of course, this only demonstrates how important the different parameters are, given the observed data. Without the policy reform something else might have happened in the market, but clearly our results indicate that the index price policy had a significant impact on competition is this market.

The results are given in the graph below.

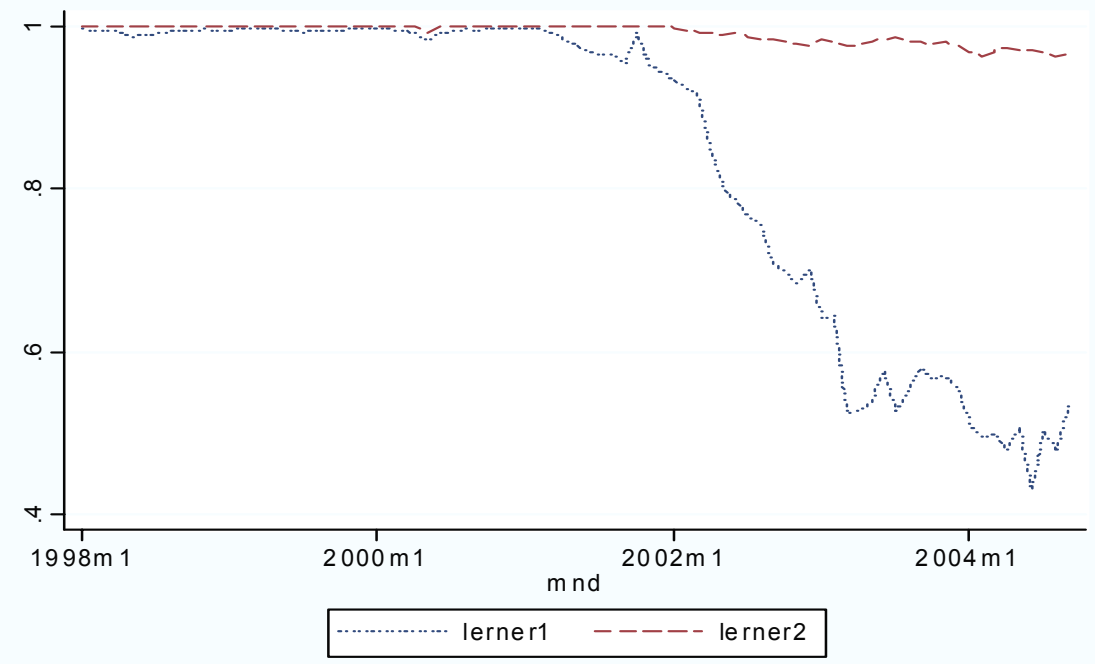

\footnotetext{
${ }^{5}$ Lerner 1 includes $\mathrm{a}_{2}$ in demand function for generic drugs.
} 


\section{Conclusions}

In March 2003 the Norwegian government implemented yardstick based price regulation schemes on a selection of drugs experiencing generic competition. The retail price cap, termed "index price", on a drug (chemical substance) was set equal to the average of the three lowest producer prices on that drug, plus a fixed wholesale and retail margin. This is supposed to lower barriers of entry for generic drugs and to reduce market power. Using monthly data over the period 1998-2004 for the 6 drugs (chemical entities) subjected to the index price regulation, we estimate a structural model enabling us to examine the impact of the reform on both demand and market power. Our results suggest that the index price helped to increase the market shares of generic drugs and succeeded in reducing overall market power. 


\section{References}

Berndt, E. R., Pindyck, R. S. og Azolay P. (2003). "Consumption Externalities and Diffusion in Pharmaceutical Markets: Antiulcer Drugs". Journal of Industrial Economics, Vol. 51, pp. 243-270, June.

Berry S. T. (1994), “Estimating Discrete choice model of product differentiation". The RAND Journal of Economics, Volume 25, Issue 2 (summer), 242-262.

Berry S.T. (1995), Levinsohn J. Pakes A., "Automobile Prices in Market Equilibrium", Econometrica,Volume 63, 841-90.

Brenkers R., Verboven F.(2002), "Liberalizing a Distribution System the European Car Market. CEPR Discussion Papers nr 3622.

Caves R.E., Whinston M. D., and M. A. Hurwitz (1991), "Patent expiry, entry and competition in the US pharmaceutical industry", Brookings Papers on Economic Activity. Microeconomics, 1- 48.

Coscelli A. (2000), “The importance of Doctors' and Patients' Preferences in the Prescription Decision", The Journal of Industrial Economics Vol. 3, pp. 349369.

Frank R.G., Salkever D.S. (1997), "Generic Entry and the Pricing of Pharmaceuticals", Journal of Economics \& Management Strategy. Spring. pp. 75-90.

Grabowski H., Vernon J. (1992), "Brand Loyalty; Entry, and Price Competition in Pharmaceuticals after the 1984 Drug Act", Journal of Law and Economics 35.

Hausman J., Leonard G., Zona D. (1994),“Competitive Analysis with Differentiated Products” Annales d'Economie et de Statistique Vol.34 p. 159-180.

Hellerstein J. (1998) "The importance of physician in the generic versus-trade name prescription decision", The RAND Journal of Economics Volume 29, 109136.

Hudson, J (2000): "Generic take-up in the pharmaceutical market following patent expiry. A multi-country study". International Review of Law and Economics. Volume 20. pp. 205-221. 
LMI (2005): Facts and Figures. Norwegian Association of Pharmaceutical Manufacturers.

Nevo A. (2000), "Mergers with Differentiated Products: The Case of the Readyto-Eat Cereal Industry", RAND Journal of Economics, Volume 31, 395-421

Pavcnik, N. (2002): "Do pharmaceutical prices respond to patient out-of-pocket expenses?" Rand Journal of Economics 33, Autumn 2002, pp. 469-487.

Razzolini, T. (2004): The Norwegian market for pharmaceuticals and the nonmandatory substitution reform of 2001: the case of enalapril. Memorandum 12/04. Department of Economics. University of Oslo.

Scott Morton F. (2000), "Barriers to Entry, Brand Advertising, and Generic Entry in the U.S. Pharmaceutical Industry”, International Journal of Industrial Organization, Vol. 18, No7, p. 1085-1104.

Stern S., Trajtenberg M. (1998)," Empirical Implications of Physician Authority in Pharmaceutical Decisionmaking" NBER Working Paper \#6851

Winkelmann, R. (2004): Co-payments for prescription drugs and the demand for doctor visits - Evidence from a natural experiment. Health Economics 13 (11). pp. 1081-1089. 


\section{Appendix A.}

Table A. Observed prices NOK per DDD and market shares in the 6 markets considered, annual means of monthly data, Norway 1998-2004.

Table A.1. ATC code A02BC01. Branded drug producer: Astra Zeneca. Strength 20.

\begin{tabular}{|l|l|l|l|l|l|l|}
\hline \multirow{2}{*}{ Year } & \multicolumn{2}{|l|}{ Branded drug } & \multicolumn{2}{l|}{ Parallel import } & \multicolumn{2}{l|}{ Generic drug } \\
\cline { 2 - 7 } & Price & $\begin{array}{l}\text { Market } \\
\text { share }\end{array}$ & Price & $\begin{array}{l}\text { Market } \\
\text { share }\end{array}$ & Price & $\begin{array}{l}\text { Market } \\
\text { share }\end{array}$ \\
\hline 1998 & 19.76 & 0.77 & 17.33 & 0.23 & - & 0 \\
\hline 1999 & 19.36 & 0.997 & 18.11 & 0.003 & - & 0 \\
\hline 2000 & 17.86 & 0.80 & 17.55 & 0.19 & 15.12 & 0.01 \\
\hline 2001 & 16.58 & 0.70 & 16.44 & 0.3 & - & 0 \\
\hline 2002 & 16.17 & 0.71 & 16.47 & 0.06 & 14.44 & 0.23 \\
\hline 2003 & 12.53 & 0.58 & 15.65 & 0.11 & 12.09 & 0.31 \\
\hline 2004 & 9.27 & 0.61 & - & 0 & 9.29 & 0.39 \\
\hline
\end{tabular}

Table A.2. ATC code C09AA02. Branded drug producer: MSD. Strength 20.

\begin{tabular}{|l|l|l|l|l|l|l|}
\hline \multirow{2}{*}{ Year } & \multicolumn{2}{|l|}{ Branded drug } & \multicolumn{2}{l|}{ Parallel import } & \multicolumn{2}{l|}{ Generic drug } \\
\cline { 2 - 7 } & Price & $\begin{array}{l}\text { Market } \\
\text { share }\end{array}$ & Price & $\begin{array}{l}\text { Market } \\
\text { share }\end{array}$ & Price & $\begin{array}{l}\text { Market } \\
\text { share }\end{array}$ \\
\hline 1998 & 3.85 & 0.86 & 3.81 & 0.14 & - & 0 \\
\hline 1999 & 3.83 & 0.62 & 3.8 & 0.38 & - & 0 \\
\hline 2000 & 3.33 & 0.49 & 3.46 & 0.51 & - & 0 \\
\hline 2001 & 2.68 & 0.70 & 2.89 & 0.25 & 2.60 & 0.05 \\
\hline 2002 & 2.52 & 0.51 & 2.7 & 0.24 & 2.57 & 0.25 \\
\hline 2003 & 1.92 & 0.44 & 1.98 & 0.04 & 1.94 & 0.52 \\
\hline 2004 & 1.21 & 0.36 & - & 0 & 1.18 & 0.64 \\
\hline
\end{tabular}


Table A.3. ATC code C09AA03. Branded drug producer: Astra Zeneca. Strength 10.

\begin{tabular}{|l|l|l|l|l|l|l|}
\hline \multirow{2}{*}{ Year } & \multicolumn{2}{|l|}{ Branded drug } & \multicolumn{2}{l|}{ Parallel import } & \multicolumn{2}{l|}{ Generic drug } \\
\cline { 2 - 7 } & Price & $\begin{array}{l}\text { Market } \\
\text { share }\end{array}$ & Price & $\begin{array}{l}\text { Market } \\
\text { share }\end{array}$ & Price & $\begin{array}{l}\text { Market } \\
\text { share }\end{array}$ \\
\hline 1998 & 5.70 & 1 & - & 0 & - & 0 \\
\hline 1999 & 5.60 & 1 & - & 0 & - & 0 \\
\hline 2000 & 5.24 & 1 & - & 0 & - & 0 \\
\hline 2001 & 4.84 & 0.91 & - & 0 & 4.67 & 0.09 \\
\hline 2002 & 4.71 & 0.72 & - & 0 & 4.49 & 0.28 \\
\hline 2003 & 4.05 & 0.50 & - & 0 & 4.00 & 0.50 \\
\hline 2004 & 2.94 & 0.58 & - & 0 & 2.92 & 0.42 \\
\hline
\end{tabular}

Table A.4. Atc code N06AB04. Branded drug producer: H. Lundbeck. Strength 20.

\begin{tabular}{|l|l|l|l|l|l|l|}
\hline \multirow{2}{*}{ Year } & \multicolumn{2}{|l|}{ Branded drug } & \multicolumn{2}{l|}{ Parallel import } & \multicolumn{2}{l|}{ Generic drug } \\
\cline { 2 - 7 } & Price & $\begin{array}{l}\text { Market } \\
\text { share }\end{array}$ & Price & $\begin{array}{l}\text { Market } \\
\text { share }\end{array}$ & Price & $\begin{array}{l}\text { Market } \\
\text { share }\end{array}$ \\
\hline 1998 & 9.99 & 1 & & 0 & - & 0 \\
\hline 1999 & 9.74 & 1 & & 0 & - & 0 \\
\hline 2000 & 9.38 & 1 & & 0 & - & 0 \\
\hline 2001 & 9.12 & 1 & & 0 & - & 0 \\
\hline 2002 & 9.05 & 0.89 & 9.03 & 0.01 & 7.99 & 0.1 \\
\hline 2003 & 8.02 & 0.56 & 8.18 & 0.002 & 7.89 & 0.438 \\
\hline 2004 & 6.73 & 0.38 & - & 0 & 6.74 & 0.62 \\
\hline
\end{tabular}


Table A.5. Atc code R06AE07. Branded drug producer: UCB Pharma. Strength 10.

\begin{tabular}{|l|l|l|l|l|l|l|}
\hline \multirow{2}{*}{ Year } & \multicolumn{2}{|l|}{ Branded drug } & \multicolumn{2}{l|}{ Parallel import } & \multicolumn{2}{l|}{ Generic drug } \\
\cline { 2 - 7 } & Price & $\begin{array}{l}\text { Market } \\
\text { share }\end{array}$ & Price & $\begin{array}{l}\text { Market } \\
\text { share }\end{array}$ & Price & $\begin{array}{l}\text { Market } \\
\text { share }\end{array}$ \\
\hline 1998 & 3.51 & 1.0 & - & 0 & - & 0 \\
\hline 1999 & 3.50 & 1.0 & - & 0 & - & 0 \\
\hline 2000 & 3.51 & 1.0 & - & 0 & - & 0 \\
\hline 2001 & 3.61 & 0.99 & 3.61 & 0.01 & - & 0 \\
\hline 2002 & 3.61 & 0.63 & 3.60 & 0.1 & 3.14 & 0.27 \\
\hline 2003 & 2.98 & 0.36 & 3.21 & 0.04 & 2.85 & 0.60 \\
\hline 2004 & 2.31 & 0.34 & - & 0 & 2.42 & 0.66 \\
\hline
\end{tabular}

Table A.6. Atc code R06AX13. Branded drug producer: Schering-Pl. Strength 10.

\begin{tabular}{|l|l|l|l|l|l|l|}
\hline \multirow{2}{*}{ Year } & \multicolumn{2}{|l|}{ Branded drug } & \multicolumn{2}{l|}{ Parallel import } & \multicolumn{2}{l|}{ Generic drug } \\
\cline { 2 - 7 } & Price & $\begin{array}{l}\text { Market } \\
\text { share }\end{array}$ & Price & $\begin{array}{l}\text { Market } \\
\text { share }\end{array}$ & Price & $\begin{array}{l}\text { Market } \\
\text { share }\end{array}$ \\
\hline 1998 & 3.73 & 0.94 & - & 0 & 3.66 & 0.06 \\
\hline 1999 & 3.72 & 0.94 & 3.60 & 0.01 & 3.72 & 0.05 \\
\hline 2000 & 3.69 & 0.91 & 3.62 & 0.03 & 3.57 & 0.06 \\
\hline 2001 & 3.70 & 0.94 & 3.88 & 0.01 & 3.62 & 0.05 \\
\hline 2002 & 3.71 & 0.82 & 3.59 & 0.04 & 3.48 & 0.14 \\
\hline 2003 & 3.32 & 0.597 & 3.56 & 0.003 & 3.30 & 0.04 \\
\hline 2004 & 2.89 & 0.48 & - & 0 & 2.89 & 0.52 \\
\hline
\end{tabular}

